\title{
Ranks of Difficulty and Frequency of Learning Attitude of Non-English Majors on Lecture-Discussion in a South Korean University
}

\author{
Ian Done D. Ramos ${ }^{1}$ \\ ${ }^{1}$ The University of Suwon, South Korea \\ Correspondence: Dr. Ian Done D. Ramos, The Graduate School of the Department of English Language and \\ Literature, The University of Suwon, 17-gil Wauan, Bongdam-eup, Hwaseong City, Gyeonggi-do, South Korea \\ 445-743
}

Received: January 26, 2014 Accepted: February 6, $2014 \quad$ Online Published: March 7, 2014

doi:10.5430/ijelt.v1n2p1 URL: http://dx.doi.org/10.5430/ijelt.v1n2p1

\begin{abstract}
This paper determined university students' ranks of difficulty on lecture-discussion in terms of: 1) listening comprehension, 2) teacher's speech production, 3) vocabulary, and 4) contents of lesson. Rank and frequency of attitude related to these difficulties manifested by these students in English classes were also identified. With the data gathered through 128 survey questionnaires, 7 focused group discussions, and 10 interviews with foreign English teachers/professors, the results were sought. As for the difficulties on listening comprehension, listening once and understanding a message ranks first (47\%). The researcher concludes that these students found listening a problem because they did not have enough proficiency to support understanding during lecture-discussion. As for the difficulties in understanding teacher's speech production, discriminating good pronunciation from bad ones ranks first (47\%). In conclusion, the students' difficulties were caused by less (or no enough) recognition of English phonetics as they did not show any verbal and non-verbal responses, even when a teacher realized mistakes in her/his pronunciation. As for the difficulties in understanding vocabulary, understanding words when a teacher uses them in a fast conversation or lecture is the most difficult (43\%). It is concluded that these students failed in this aspect due to lack of exposure to the English language in general; and, a teacher ended up using simpler words and even doing translation method to facilitate learning. As for the difficulties in understanding contents of lesson, learning a concept or a topic when a teacher presents its examples first ranks first (20\%). The researcher concludes that there was no link between understanding of words a teacher used in English classes and amount of previous knowledge a student had learned. And, as for the attitude shown during the lecture discussion, going out when I don't understand teacher's lectures is the most frequently done ( $72 \%$ indicating never). It is concluded that the students were found to be passive in the lecture discussion and shy in the activities, while others remained though with commitment when activities seemed extremely interesting and fun. The researcher then recommends that inputs for a curriculum training program on lecture-discussion may be designed for English teachers to address students' real needs.
\end{abstract}

Keywords: theory of learning, elaboration theory, lecture, discussion, lecture-discussion, encouraging intake heard for acquisition, utilizing language heard for acquisition

\section{Introduction}

About three decades ago, Korean schools did not consider English as a medium of instruction in English classes where local teachers were made to teach. These days, more and more courses taught by foreign professors are now being offered at the university in hopes to reshape students' academic performance and future professional endeavors as well as to develop the right attitude for communicative tasks. Two of the criteria for achieving communicative competence are the coping with teacher's lecture discussion that entails student's listening skills and class activities that lead students to perform learning into completing essays, exams, and oral presentations.

However, there are still issues on providing lectures in English at the university level. Kim Jae-won (2013) reported that "four out of ten students in a nationwide survey did not understand them" (p. 1). Additionally, she mentioned that according to a report co-written by Busan Metropolitan Council researcher Hong Ji-young and Busan National University of Education Professor Lee Kwang-hyun, only 37.1 percent of university students out of 2,400 in a survey conducted nationwide said that they could understand 60 percent of lectures in English. She restated that according 
to experts, "colleges need to focus on the writing skills of students rather than offering lectures in English only" (p. 1). She also reported the suggestions made by Korea University lecturer Oh Seung-yeon (2012) that "English classes should be tied to official English proficiency tests, such as the Test of English for International Communication (TOEIC) and Test of English as Foreign Language (TOEFL), and colleges need to implement English proficiency graduation certification program by providing classes for official English proficiency tests" (p. 1).

In one of the universities in South Korea's Jeollabuk-do province, the students also seem to have difficulties in lecture discussion because a large group of students are placed in one class, without considering their common interest, motivation, and language proficiency levels.

Thus, this paper investigates the non-English majors with the following research question guide: 1) what difficulties do first year and second year students and English teachers encounter in English language classroom in terms of: 1.1) listening comprehension, 1.2) teacher's speech production, 1.3) vocabulary, and 1.4) contents of lesson?; 2) what attitudes related to these difficulties are shown by first year and second year students in English classes?; 3) how can these difficulties be addressed in relation to their attitudes that are observed in English classes of the first and second year levels?; and 4) corollary to the above questions, what inputs for a curriculum training program can be proposed to address students' language needs on lecture-discussion? This concern is worth investigating because lectures in English at the university are basic foundations in preparation for global internship program and employment-seeking.

\section{Theoretical Background}

\subsection{The Theory of Learning}

Students in an English as a Foreign Language (EFL) setting are expected to have more difficulties in developing strategic and communicative competence due to the nature of their communicative environments. These students study English for university entrance exams and employment purposes only. Most of the time, they do not have the comfort of speaking the language due to lack of resource people whom they can practice with to further develop their potentials. Thus, students' learning styles trying to manifest competence can easily be identified in classroom discussion and activities.

Kolb's learning theory as shown below has four distinct learning styles (or preferences), namely: 1) diverging (CE/RO), 2) assimilating (AC/RO), 3) converging (AC/AE), and 4) accommodating (CE/AE).

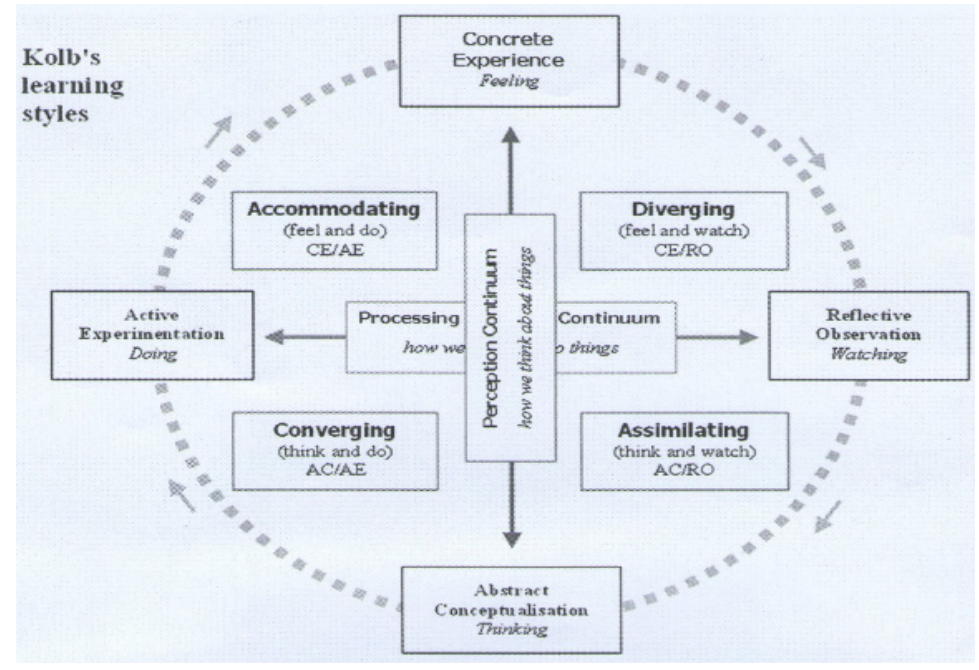

Figure 1. Kolb's Learning Styles (adopted from Kolb diagrams, May 2006)

Diverging (feeling and watching). It refers to the preference to watching rather than doing. This type of learners collects pieces of "information and use imagination to solve problems using concrete situations requiring ideas-generation, for example: brainstorming," soliciting or eliciting ideas or opinions from a group, accommodating personal reactions, etc. (Kolb, 2013). In a group activity, some students are more comfortable gathering information for presentation or interaction. In Ramos' (2013) study, Korean students were more motivated to learn English because grouping or pairing helped them compare and contrast the amount of their learning with fellow students' as basis for improvement. 
Assimilating (watching and thinking). It refers to the preference to concise, logical approach. That means that "understanding wide-ranging information and organizing in a clear logical format" are more essential than people (Kolb, 2013). Kolb explains that these learners are into readings, lectures, exploring analytical models, and having time to think things through. As for the English language education approach in Korea, students have been exposed to passive approach where most of them just listen to lectures, read books, and follow teacher's instructions without trying to ask why and how, and they are likely to be comfortable with this. Kookmin University Prof. Andrei Lankov (2012) saw this as the influence of Confucianism which refers to "much emphasis on the virtue of social hierarchy" that causes students to prohibit themselves from speaking up in front of older people unless being asked to say something. Rajabi and Ketabi (2012) pointed out that "learners are made aware of the various dimensions of culture as well as the rules of the language" (p. 707).

Converging (doing and thinking). It refers to the preference to technical tasks, and this concept is less interested in interacting with people. This type of learners is likely to be inclined in "experimentation with new ideas, simulation and working with practical applications" (Kolb, 2013). Smart students studying in Korea and those who have studied abroad are likely to be more motivated to undergo challenging communicative and critical thinking-driven activities. Ramos' (2012) study revealed that they were more interested to succeed with their learning styles whenever they had felt improvement on skills outside and inside classes.

Accommodating (doing and feeling). This learning style refers to the 'hands-on' and relies on intuition rather than logic. In other words, learners think and act according to their guts. This type of learners tends to be successful because of "new challenges and experiences and plans" that accommodate learning (Kolb, 2013). Strong support system motivates students to complete tasks according to the expectations and experiences they have possessed. Parents, teachers, and learning environments heighten students' spirit of reshaping their view of life by challenging themselves for communicative undertakings. Most university students in Korea plan a lot in preparation for job-seeking or internship abroad. Part of the plan is to take TOEFL, TOEIC, and other standard exams. In a class scenario, students make use of the opportunity to interact with foreign teachers in any way possible.

Kolb explains that "most people clearly exhibit clear strong preferences for a given learning style. The ability to use or 'switch between' different styles is not one we should assume that comes easily or naturally to many people." In other words, a learner may develop these learning styles based on the impact of difficulty level of the learning situations, level of interests or motivation, feelings or moods, etc.

Furthermore, it is also important to note that Kolb's four distinct learning styles are based on a four-stage learning cycle or a 'training cycle'. According to Kolb, this model (see Figure 1) provides "both a way to understand individual people's different learning styles and also an explanation of a cycle of experiential learning that applies to us all." He also explains that the four-stage cycle of learning activate "'immediate or concrete experiences' that provide a basis for 'observations and reflections,' and "these observations and reflections are developed into 'abstract concepts' producing new implications for action which can be 'actively tested' in turn creating new experiences".

With the theory of learning explained by Kolb, Korean students can be assessed on how much learning they have had in the English language implementation and what impact it contributes to their lives. Likewise, teachers and curriculum developers may now review which areas of teaching, types of activities, and use of materials are effective to help students develop critical thinking and sense of communicative responsibilities.

\subsection{Elaboration Theory in Lecture-Discussion}

Concepts and messages in conversation, discussion, or lecture are further understood when elaboration is processed with appropriate techniques. Kelly (2014) defines lecture as "a teaching method where an instructor is the central focus of information transfer." Typically, a teacher stands before a class and presents information by writing on a board or using a powerpoint slides (with pictures or illustrations) projected on the white screen, and students are taking down notes while listening to the lecture. As for discussion, Applegate (1969) cited in Gall and Gillett (2001) defines it as "open and active participation; however, in most instances, it becomes a limited dialogue between the teacher and a few pupils, with the remaining ones sitting mute and inactive" (p. 78). As discussion offers many thought-provoking comments or critical thinking-driven processes, a teacher often asks students to discuss among themselves. However, others may not feel comfortable due to communicative issues and other related factors. In order to maintain a good flow of discussion, Hadjioannou (2007) argued that students must first listen to and understand what other students have discussed so as to have meaningful interaction. Meaningful interaction means that elaboration of concept or situation should be effectively done among students and/or with teachers.

Elaboration is designed to activate cognitive aspect. Reigeluth (1992) explains that "the instruction in Elaboration 
theory should be organized in increasing order of complexity for optimal learning." In other words, the simplest procedural tasks should be taught first before elaborating the most complex tasks so that "the learner may be able to develop a meaningful context into which subsequent ideas and skills can be assimilated" (ibid.). For students attending lectures and discussions, elaboration processed by teachers or even students themselves in independent learning is therefore very essential to gain information for practical situations; otherwise, teaching and learning are static and not functional to both teachers and students.

Hackathorn et al's (2011) study titled, "Learning by Doing: An Empirical Study of Active Teaching Techniques," investigated lecture and discussion methods. As for lecture, the finding revealed that correct scores on knowledge level assessments obtained in the lecture method were significantly lower than both comprehension and application, "perhaps because knowledge level assessments are often based on rote memorization, such as knowing which definition describes a particular construct" (pp. 48-49). And as for discussion, the finding revealed that scores on comprehension were lower than both knowledge and application level items, as shown in students' "wrong thoughts, misleading information, and even mythology and urban legends" (p. 49). However, the constructs taught using discussion obtained $80 \%$ (satisfactory) in correct responses on application and knowledge level items (p. 49). He concluded that "allowing students to interact via discussions is an effective teaching technique, perhaps because as they repeatedly hear vocabulary words throughout the discussion, it lends itself to increased memory" (p. 49).

Reigeluth (1992) claims that "the elaboration approach results in the formation of more stable cognitive structures and therefore better retention and transfer, increased learner motivation through the creation of meaningful learning contexts, and the provision of information about the content that allows informed learner control." By so-doing, he proposes seven major strategy components, such as: "1) an elaborative sequence, 2) learning prerequisite sequences, 3) summary, 4) synthesis, 5) analogies, 6) cognitive strategies, and 7) learner control." These seven major strategy components are always useful in any classroom teaching methods.

With the combination of lecture and discussion concepts, another teaching method can be established, that is lecture-discussion which refers to the transferring of information to students by a teacher with interactive question-answer moments in between lectures to facilitate active learning. Thus, elaboration through discussion helps transact teaching-learning inputs and eventually, students' output will become more meaningful. Marmet's study (1977) made use of a non-randomized pretest, posttest design using both an experimental group and a control group. The study concluded that "the lecture-discussion method produced mean gains in learning during the treatment" ( $\mathrm{p}$. 42).

However, lecture-discussion in English may affect students' attitude into becoming either worse or better in a Foreign Language (EFL) setting, depending on the contributing factors attracted by students, since English has not been fully used as a medium of instruction in South Korea.

\subsection{Learning Attitude}

In English language classroom in Korea, careful consideration of student's attitude and interest is a big factor in achieving language proficiency since English is not treated as an official language in the country. Some of them are not interested to learn the language; they are just required to attend such class without well-defined motivation and interest.

Krashen (2002) presents two attitudinal factors that relate to second language acquisition, 1) encouraging intake and 2) utilizing language heard for acquisition. In encouraging language intake, "others have said that motivational variables... determine whether or not the student avails himself of... informal language contexts" (Gardner, Smythe, Clement, \& Gliksman, 1976, cited in Krashen, 2002, p. 21). Krashen explains that "they are simply factors that encourage acquirers to communicate with speakers of the target language, and thereby obtain the necessary input, or intake, for language acquisition" (ibid.).

In utilizing the language heard for acquisition, "performers simply heard a second language with understanding that appears to be necessary but is not sufficient for acquisition to take place" (ibid.).. That means that it is a necessity for students to be 'open' to the input, not only understand it, according to him. For Dulay and Burt (1977) as cited in Krashen (ibid.), performers with high or strong socio-affective filters will acquire less of the language directed at them, as less input is "allowed in" to the language-acquisition device.

In Ramos' study (2012) on learning attitude towards communicative activities, the data explained that Korean students never thought of not following instructions just because they were confident to speak English. In fact, they believed that following instructions would help them succeed in the communicative activities. Additionally, they never went out nor skip classes the following day, whenever there was a speaking activity. They treated it as a 
challenging part; while, others thought of it as tiring and useless as they were just forced to come for the sake of attendance. Only few felt good though when they were able to communicate in English. In fact, they were excited to practice as it is useful in job-seeking, and were proud eventually when they had improved or achieved something positive.

Moreover, Krashen (2002) also presents two types of motivation, integrative motivation and instrumental motivation, that contribute to students' attempt for second language proficiency. He defines integrative motivation as "the desire to be like valued members of the community that speak the second language" (p. 22). Accordingly, integrative motivation encourages the learner to interact with other users of the language considering same interest of topic, and thereby obtain intake. On the other hand, he defines instrumental motivation as "the desire to achieve proficiency in a language for utilitarian, or practical reasons, may also relate to proficiency". It encourages the learners to interact with L2 speakers to achieve good results of acquisition. He concludes that "when the practical value of second language proficiency is high, and frequent use necessary, instrumental motivation may be a powerful predictor of second language acquisition" (p. 23).

Ramos (2012) observed students' frequency of attitudes that clearly determined that students were only participative in communicative activities when they were not conscious of grammar and when they knew they could talk a lot freely about any interesting topics with teachers being flexible. Dansereau (1985) and McCombs (1988) cited in Oxford, 2012, p. 125) show results that "a number of the best learners use affective and social strategies to control their emotions, to stay motivated, to cooperate, and to get help." Some of them manifested their limits of ability in 'conversation time' though, due to lack of language exposure, previous classroom orientation, and other personal issues. Schumann (1975) as cited in Krashen (2002, p. 23) suggests that "... the natural factors that induce ego flexibility and lower inhibitions (assumed to relate to increased empathy) are those conditions which make the learner less anxious, make him feel accepted and make him form positive identifications with speakers of the target language".

English teachers in Korea find right attitude as an effective element in the acquisition and learning of English skills (Ramos, 2012). When the student feels at ease in the classroom and likes the teacher, he may seek out intake by volunteering ('high input generator') and may be more accepting of the teacher as a source of intake (Seliger, 1977; cited in Krashen, 2002). Furthermore, students' positive attitude towards the English language classroom may also be manifestations of self-confidence and motivation, and they were likely to have more results in acquiring the language.

With the three literature reviews and their respective empirical studies discussed above, educators would be given light to the understanding of students' difficulties on lecture-discussion in English, in addition to the findings of this current study. In summary, below is the theoretical-conceptual framework of this study.

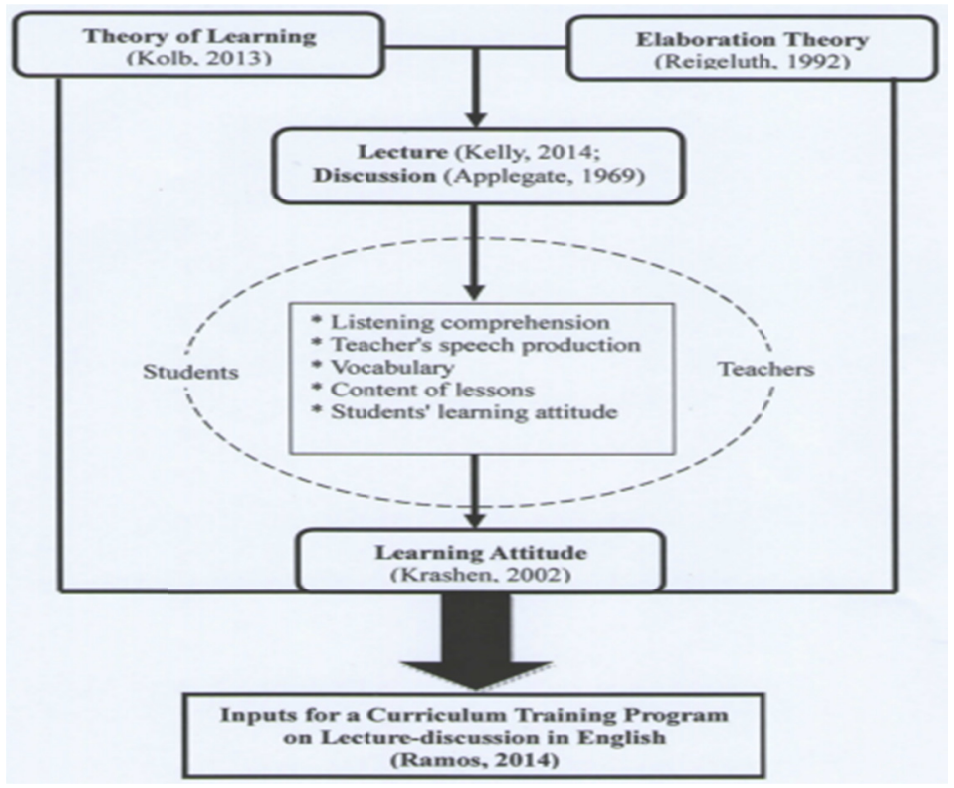

Figure 2. Theoretical-Conceptual Framework of the Study (Ramos, 2014) 


\section{Research Methodology}

\subsection{Research Design}

This study is exploratory-quantitative-interpretative in orientation. This means that the design is non-experimental, the data collected are primarily quantitative, and the analysis is highly interpretative.

\subsection{Research Participants}

The data collection from the research participants was gathered in one of the universities run by Buddhist Foundation in South Korea.

Selected first year and second year students and English teachers at this University were made to participate in the study. Specifically, for questionnaire survey, there were 128 students ( 70 first years and 58 second years) chosen randomly among English classes and 10 foreign teachers/professors ( 5 content professors and 5 professional English teachers); for FGD (Focused Group Discussion), there were 7 groups ( 7 to 10 students per group); and for interview, same number of foreign professors was included.

\subsection{Research Procedure}

With the assistance of the Coordinator at the Center for International Development, the researcher sought permission for survey questionnaire, FGDs, and interviews. The researcher indicated in the letter to be sent to the office heads the purpose of the study and the number of the respondents needed in data collection.

The data collection through survey questionnaires, FGDs, and interviews was simultaneously done. The researcher collected the data from the respondents during class hours. With coordination of the professors, the researcher distributed the questionnaire and did FGDs with students in the class at any class schedule. Questionnaires were distributed to them before a professor started his/her class. FGD members were selected randomly and they were interviewed 30 minutes before each class ended. The ten professors were also interviewed and distributed survey questionnaires after class or office hours.

The researcher was guided with a set of guide questions while doing the FGDs and interviews. The questions asked during interviews and FGDs were not only aimed at validating the data from the questionnaires, but were also considered as additional sources of information.

\subsection{Treatment of Data}

The number of survey respondents was determined by purposive-cluster random sampling with the Slovin's formula. This formula was also used to determine the number of students in the FGD as well as the teachers who were interviewed. Frequency count was determined by the percentage formula.

The study used quantitative data since frequency counts for the survey results through questionnaire were considered. Moreover, qualitative approach was also employed since interviews with the English teachers and FGDs with students were also considered. Both approaches mentioned are exploratory, since the primary objective of the study is to provide deeper insights into the problem.

Based on qualitative perspectives, this study employed triangulation in the sense that multiple methods of data collection and multiple sources of information were considered. Multiple methods of data collection included survey questionnaire, interview, and FGD. Multiple sources of information were first and second year students, ten English teachers (five content professors from Physical Therapy, Medical Technology, Nursing, Ophthalmic Optics, and Public Administration departments; and five professional English teachers), and course outlines or syllabuses used in English classes.

The analysis of the data is primarily interpretative. This means that the researcher describes the students' difficulties and attitude in lecture discussion stated in the questionnaires, FGDs, and interviews.

\section{Results}

Tables 1 to 4 present the ranks of difficulty on lecture-discussion in terms of listening comprehension, teacher's spech production, vocabulary, and contents of the lessons. Table 5 presents the rank and frequency of learning attitude on lecture-discussion.

Table 1 presents the difficulties on listening comprehension. 
Table 1. Rank of difficulty on listening comprehension during lecture-discussion

\begin{tabular}{lccccccc}
\hline & Easy & $\%$ & Moderate & $\%$ & Difficult & $\%$ & Rank \\
\hline 1. Listening once and understanding amessage & 14 & 11 & 54 & 42 & 60 & $\mathbf{4 7}$ & $\mathbf{1}$ \\
2. Listening for specific details & 14 & 11 & 55 & 43 & 59 & $\mathbf{4 6}$ & $\mathbf{2}$ \\
3. Listening for main ideas & 30 & 23 & 85 & 66 & 13 & $\mathbf{1 0}$ & $\mathbf{3}$ \\
\hline
\end{tabular}

In the table above, among the three skills, listening once and understanding a message ranks first (47\%); followed by listening for specific details (46\%); and listening for main ideas (10\%).

Table 2 below presents the difficulties in understanding teacher's speech production.

Table 2. Rank of difficulty on teacher's speech production during lecture-discussion

\begin{tabular}{lccccccc}
\hline & Easy & $\%$ & Moderate & $\%$ & Difficult & $\%$ & Rank \\
\hline $\begin{array}{l}\text { 1. Discriminating good pronunciation from } \\
\text { bad ones }\end{array}$ & 12 & 9 & 56 & 44 & 60 & $\mathbf{4 7}$ & $\mathbf{1}$ \\
$\begin{array}{l}\text { 2. Imitating teacher's way of pronunciation } \\
\text { 3. Understanding teacher's pronunciation exactly }\end{array}$ & 31 & 24 & 67 & 52 & 30 & $\mathbf{2 3}$ & $\mathbf{2}$ \\
\hline
\end{tabular}

The above table shows that among the three skills, discriminating good pronunciation from bad ones ranks first (47\%); followed by imitating teacher's way of pronunciation (23\%); and, understanding teacher's pronunciation accurately (13\%).

Table 3 below presents the difficulties in understanding vocabulary.

Table 3. Rank of difficulty on vocabulary during lecture-discussion

\begin{tabular}{lccccccc}
\hline & Easy & $\%$ & Moderate & $\%$ & Difficult & $\%$ & Rank \\
\hline $\begin{array}{l}\text { 1. Understanding words when a teacher } \\
\text { uses them in a fast conversation or }\end{array}$ & 15 & 12 & 57 & 45 & 55 & $\mathbf{4 3}$ & $\mathbf{1}$ \\
$\begin{array}{l}\text { lecture } \\
\begin{array}{l}\text { 2. Understanding the meaning of words } \\
\text { when a teacher uses them in sentences }\end{array}\end{array}$ & 27 & 21 & 77 & 60 & 24 & $\mathbf{1 9}$ & $\mathbf{2}$ \\
$\begin{array}{l}\text { 3. Understanding the meaning of words } \\
\text { when a teacher applies word conjugation } \\
\text { or affixes }\end{array}$ & 22 & 17 & 84 & 66 & 22 & $\mathbf{1 7}$ & $\mathbf{3}$ \\
\hline
\end{tabular}

In the above table, understanding words when a teacher uses them in a fast conversation or lecture is the most difficult; followed by understanding the meaning of words when a teacher uses them in sentences; and, understanding the meaning of words when a teacher applies word conjugation or affixes -- which rank first (43\%), second (19\%), and third (17\%), respectively.

Table 4 presents the difficulties in understanding contents of the lesson.

Table 4. Rank of difficulty on contents of the lesson during lecture-discussion

\begin{tabular}{lccccccc}
\hline & Easy & $\%$ & Moderate & $\%$ & Difficult & $\%$ & Rank \\
\hline $\begin{array}{l}\text { 1. Learning a concept or a topic when a teacher } \\
\text { presents its examples first }\end{array}$ & 26 & 20 & 77 & 60 & 25 & $\mathbf{2 0}$ & $\mathbf{1}$ \\
$\begin{array}{l}\text { 2. Learning a concept or a topic when a teacher } \\
\text { presents its definitions or generalizations first }\end{array}$ & 26 & 20 & 80 & 63 & 22 & $\mathbf{1 7}$ & $\mathbf{2}$ \\
$\begin{array}{l}\text { 3. Learning a concept or a topic when a teacher } \\
\text { presents visual aids and actions }\end{array}$ & 42 & 33 & 76 & 59 & 10 & $\mathbf{8}$ & $\mathbf{3}$ \\
\hline
\end{tabular}

The table above shows that among the three skills, learning a concept or a topic when a teacher presents its examplesfirst ranks first (20\%); learning a concept or a topic when a teacher presents its definitions or 
generalizations, second (17\%); and, learning a concept or a topic when a teacher presents visual aids and actions, third $(8 \%)$.

Table 5 presents the attitudes shown during the lecture discussion.

Table 5. Rank and frequency of learning attitude on lecture-discussion

\begin{tabular}{|c|c|c|c|c|c|c|c|c|c|c|c|}
\hline & always & $\%$ & usually & $\%$ & sometimes & $\%$ & seldom & $\%$ & never & $\%$ & Rank \\
\hline $\begin{array}{l}\text { 1. Going out when I don't } \\
\text { understand the teacher's } \\
\text { lecture }\end{array}$ & 0 & 0 & 5 & 4 & 15 & 12 & 16 & 12 & 92 & 72 & 1 \\
\hline $\begin{array}{l}\text { 2. Listening attentively to the } \\
\text { lecture and having my } \\
\text { review notes }\end{array}$ & 7 & 5 & 33 & 26 & 61 & 48 & 19 & 15 & 8 & 6 & 2 \\
\hline $\begin{array}{l}\text { 3. Not asking my teacher to } \\
\text { repeat points that I don't } \\
\text { understand; just remaining } \\
\text { quiet }\end{array}$ & 7 & 5 & 29 & 22 & 43 & 34 & 29 & 23 & 20 & 16 & 3 \\
\hline
\end{tabular}

Among the situations shown in the above table, going out when I don't understand teacher's lectures is the most frequently done; followed by listening attentively to lectures and having my review notes; and, not asking my teacher to repeat points that I don't understand and just remaining quiet -- which rank first (72\% indicating never), second (48\% indicating sometimes) and third (34\% indicating sometimes), respectively.

\section{Discussion of the Results}

The data in Table 1 (Rank of difficulty on listening comprehension during lecture-discussion) explain that some students found listening once and understanding a message the most difficult due to inefficiency of processing what is being heard. Generally, they could not cope with the skill; but when done for several times in a slow mode, they could though. For some allied medical students who are believed to be smart and studious, they could cope with this skill with little conscious attention to individual words. As for listening for specific details, only few could do so when teachers taught them as they had been trained in lower years, while others could not as they were not interested as shown in their tiresome behavior. And as for listening for main ideas, they could not due to pre-occupied condition and failure to recognize pronunciation. Others may remember key words and were able to use these words to understand the message being implied (not all the time though).

Since these students were not exposed to lecture-discussion in English conducted by foreign English professors, such difficulty on listening, along with the manifested behavior or attitude, surely happens. Rost (1994, pp. 141-142) cited in Nunan (2012, p. 239) points out that listening is essential in language teaching due to its input being provided to students; "without understanding input at the right level, any learning simply cannot begin" (p. 239). At some point of learning, "nonnative listeners recognize only part of what they hear and have to make guesses which link these fragmented pieces of text" (Field, 2012, p.244). Field's view in this particular language situation could also describe why the students are pre-occupied that may change their behavior or attitude. However, good students were able to succeed due to their personal goals. According to Oxford (2012), "skilled L2 learners select strategies that work well together and that are tailored to the requirements of the language tasks; for high-performing L2 learners, cognitive and meta-cognitive strategies often go together" (p. 126).

The data in Table 2 (Rank of difficulty on teacher's speech production during lecture-discussion) explain that as for discriminating good pronunciation from bad ones, these students were simply not good at it and that, no effort was shown. In some instances, poor students could distinguish good from bad pronunciation though; there were few interested students who were sensitive enough to pronunciation. As for imitating teacher's way of pronunciation, they could hardly do such, like in determining /r/ sound (e.g. really) that is naturally replaced with /1/ sound (i.e. lily), and they still have the trace of Korean accent. Repetition may help in this area. And as for understanding teacher's pronunciation accurately, they could not do so even in normal speed. In fact, they asked for repetition in a slow manner. This was reinforced by writing key words on the board. Others, however, could understand when a teacher pronounced or enunciated words well in controlled speech, because exposing to their native English teachers in lower years was meaningful to them.

Since these students are twenty years old and above, English pronunciation or accent acquisition would be hard to 
master. Based on the critical period hypothesis, "it is virtually impossible for adults to acquire native-like pronunciation in a foreign language" (Jones, 2012, p. 179; also see Burrill, 1985). In other words, "imitation activities might be more successful with younger learners; older learners might benefit from a more descriptive or analytic approach" (Brown, 1992; cited in Jones, 2012, p. 179).

The data in Table 3 (Rank of difficulty on vocabulary during lecture-discussion) explain that these students could hardly understand words when a teacher used them in a fast conversation or lecture. Since, it was the most difficult for them, they resulted to stop paying attention to it; some could only understand easy words though. Moreover, they could not understand the meaning of words when a teacher used them in sentences; they may cope with the skill, only when being explained with actions and new words written on the board. Also, poor students could only understand the meaning of words when a teacher applied word conjugation or affixes by writing them on the board in column/group. However, conjugation was only discussed to a limited degree, when time was not sufficient, and in some instances, these were not used nor discussed at all. A teacher ended up using simpler words and even doing translation method to facilitate learning.

According to Hunt and Beglar (2012), "translation has a necessary and useful role in L2 learning, but it can hinder progress if it is used to the exclusion of L2-based techniques" (p. 260). Further, Prince (1996, p. 488; cited in Hunt and Beglar, 2012, p. 261) argues that "simply knowing translations for L2 words does not 'guarantee that learners will be successfully accessed for use in an L2 context', because knowing a word means knowing more than just its translated meaning or its L2 synonyms." These views on translation method employed in English classes in high school and lower years have been practiced, since local English teachers in Korea are made to teach. This orientation has been carried over by these students at the university level.

The data in Table 4 (Rank of difficulty on contents of lesson during lecture-discussion) explain that as for learning a concept or a topic when a teacher presents its examples first, the students could somehow carry on the skill, only when a teacher used interesting and funny examples. As for learning a concept or a topic when a teacher presents its definitions or generalizations, they were confused more as giving definitions requires a lot of listening and word use; poor students could sometimes do so, only when a teacher used easy way of defining terms. And as for learning a concept or a topic when a teacher presents visual aids and actions, they found it as a motivator to arouse their interests and attention span.

Furthermore, there seems to have no link between understanding of words a teacher used in English classes and amount of previous knowledge a student had learned. A factor, like inconvenient class schedule, could also lessen students' ability to stay focus on discussions, as emphasized in the FGDs and interviews.

This issue dwells more on the amount of reading exposure. It is believed that reading develops learners' proper use of vocabulary and how it is used in context. Hunt and Beglar (2012) support that "fluency partly depends on developing sight vocabulary through extensive reading and studying high-frequency vocabulary" (p. 262). Context may only be developed when learners are exposed to content of reading selections to eventually create appreciation of gathered information and reading skills. Reading is a basis for determining student's amount of comprehension and appreciation of language tasks. However, since these EFL students from various provinces in Korea were non-English majors, it could be implied that they were not motivated to learn effective reading skills and lecture discussion in English.

The data in Table 5 (Rank and frequency of attitude on lecture-discussion) explain that most students went out whenever they did not understand teacher's lectures, without asking questions for clarification; while, others just remained quiet and did not participate in class. Sometimes, some of them listened attentively to lectures, while only few of them used their review notes for future reference. However, there were still few students who sometimes asked their teachers to repeat points that they did not understand, but they seemed to just remain quiet all throughout the class whether they were satisfied or not.

Such frequencies of attitudes were drawn from students being passive in the lecture-discussion and shy in the activities. In other classes where they were not comfortable in class, some would really go out with various alibis or just remained but doing something not expected of a class, as emphasized in FGDs and teacher interviews. Others remained though with commitment when activities seemed extremely interesting and fun. Generally, they still survived in English classes. Oxford (2012) believes that "when allowed to learn in their favorite way, unpressured by learning environment or other factors, students often use strategies that directly reflect their preferred learning" (p. 127).

The ranks of difficulties on various aspects of lecture-discussion as well the rank and frequency of learning attitude 
toward it have presented the data with their corresponding analysis and interpretation. These are the bases to hopefully improve the implementation of lecture-discussion in English if support system in this particular university is solid to arrive at one goal.

\section{Conclusions and Recommendations}

Qualified local English teachers who patronize bilingualism (English and Korean) have turned out high school classes as well as lower years less competent on the aspect of lecture-discussion in English. Thus, difficulties on a lecture discussion and other class activities implemented by foreign teachers at the university level seem to impede students' goals to alleviate their interest and motivation in obtaining content-based learning while achieving communicative competence.

As for difficulties on listening during lecture-discussion, it is concluded that these students found listening a problem because they did not have enough proficiency to support understanding during lecture-discussion, as mentioned in the FGDs and interviews. The researcher recommends that students should be taught "to adopt a flexible range of listening strategies by holding the listening text constant (working, say, with radio news broadcast reporting a series of international events) and getting learners to listen to the text several times--however, following different instructions each time" (Nunan, 2012, p. 239). Not all students though found difficulty on listening to teachers and even audio (CD), but rather on speaking, as mentioned again in the FGDs and interviews.

As for difficulties on teacher's speech production during lecture-discussion, it is concluded that the students' difficulties were caused by less (or no enough) recognition of English phonetics as they did not show any verbal or non-verbal responses, even when a teacher realized mistakes in her/his pronunciation, as mentioned in the FGDs and interviews. The researcher then strongly recommends that "pronunciation teaching methods should more fully address the issues of motivation and exposure by creating an awareness of the importance of pronunciation and providing more exposure to input from native speakers" (Jones, 2012, p. 180).

As for difficulties on understanding vocabulary during lecture-discussion, it is believed that words are formed through sentences, which is a basic element of a language students should learn to completely understand concepts and messages presented verbally in lecture discussion. It is concluded that these students failed in this aspect due to lack of exposure to the English language in general; so, teachers ended up using simpler words and even doing translation method to facilitate learning, as mentioned in the FGDs and interviews. The researcher recommends that since:

"elaboration involves expanding the connections between what the learners already know and new information... exercises that can deepen students' knowledge of words should include the following: 1) sorting lists of words and deciding on the categories; 2) making semantic maps with lists either provided by the teacher or generated by the learners; 3) generating derivatives, inflections, synonyms, and antonyms of a word; 4) making trees that show the relationships between superordinates, coordinates, and specific examples; 5) identifying or generating associated words; 6) combining phrases from several columns; matching parts of collocations using two columns; 7) completing collocations as a cloze activity; and 8) playing collocation crossword puzzles or bingo." (Hunt \& Beglar, 2012, p. 261; also see Lewis, 1993; McCarthy \& O'Dell, 1994; Nation, 1994; Redman \& Ellis, 1990).

As for difficulties on contents of lessons during lecture-discussion, it is concluded that there was no link between understanding of words a teacher used in English classes and amount of previous knowledge a student had learned, as mentioned in the FGDs and interviews. The researcher recommends that extensive reading is one of the best ways to improve content-based learning. Grabe (2012, p. 280) supports with evidence that "the best way to learn to read (as opposed to translating, or studying) is by extensive reading." He emphasizes that "the more immediate solution rests partly with educating administrators and teachers about the importance of extensive pleasure reading (p. 280)"

And, as for rank and frequency on attitude or behavior toward lecture-discussion, it is concluded that the students were found to be passive in the lecture-discussion and shy in the activities, while others remained though with commitment when activities seemed extremely interesting and fun, as mentioned in the FGDs and interviews. The researcher recommends that students should be exposed to a strategy system that has six sets of L2 learning behaviors, namely:

"1) affective, such as anxiety reduction through laughter and meditation, self-encouragement through affirmations, and self-reward through praise and tangible reinforcement; 2) social, such as asking questions, cooperating with native speakers of the language, and becoming culturally aware; 3) metacogntive, such as 
paying attention, consciously searching for practice opportunities, planning for language tasks, self-evaluating progress, and monitoring errors; 4) memory-related, such as grouping, imaginary, rhyming, moving physically, and structured reviewing; 5) general cognitive, such as reasoning, analyzing, summarizing, and practicing; and 6) compensatory, such as guessing meanings from the context and using synonyms and gestures to convey meaning." (Oxford, 1990; cited in Oxford, 2012, p. 128)

Additionally, it is concluded that these difficulties on various aspects of lecture-discussion as well as their frequency of learning attitude had not been taken as an important element in the English language curriculum planning at the university level before the Department of English Language of this particular university implemented its program. Thus, it is necessary to take into consideration the results, conclusions, and recommendations of this paper in response to students' real needs. Real needs could be processed in terms of syllabus design, materials development, and quality support system that involves honest feedbacks from students and proper assessment by teachers and a curriculum developer. Such feedback assessment should be incorporated in lecture-discussion in English.

Thus, inputs for a curriculum training program on lecture-discussion which is directed to English teachers may include the seven sessions, namely: 1) Capacity Building and Curriculum Leadership Empowerment, 2) The Importance of Needs Analysis and Direction in Curriculum Leadership, 3) Introduction to Lecture-Discussion Method, 4) Student Assessment on their Attitude and Cultural Backgrounds for Lecture-Discussion Method, 5) Adapting Lecture-Discussion Method, 6) Student Assessment and Lesson Planning towards Globalization, and 7) The Implementation of Lecture-Discussion: Action and Reflection. Each session may include topics, objectives, learning activities, expected outcome, persons responsible, resources needed, source of funding, and time line to process knowledge and skills with the newest trend of language teaching.

Moreover, since lecture-discussion highly involves listening, the following inputs may also be considered:

A. Specific skills

1. Unfamiliar words should be identified before listening drill is done.

2. Listening for main ideas and specific details should be processed in a slow and repeated drill.

3. Checking up comprehension by expressing gathered information is also important.

4. Specific themes/situations for a specific discipline should be implemented more meaningfully.

B. Teaching tips

1. Translating unfamiliar words into Korean by a teacher and giving examples in a creative way help motivate students to focus attentively on listening texts. Students would feel amazed when a teacher can speak Korean; however, he/she should limit the use of it.

2. A teacher may control his speed for each paragraph on the first round, and let students listen again to all paragraphs naturally on the second round.

3. A teacher should encourage students to speak up their understanding from a selection by looking into a strategy that draws out their interest and motivation.

4. A teacher should use themes/situations relevant to student's level of understanding and word usage ability. For ESP classes, topics and themes should be carefully chosen to arouse level of interest and retention span.

C. Expected outcome

1. Students will feel the comfort zone that would keep them stay all throughout the class.

2. Students will be encouraged to appreciate the obtaining of accurate information. They will learn that careful listening should be given much importance.

3. Students can be assessed with how much listening proficiency they have developed as reflected in their oral participation. Amount of listening comprehension can be determined with the confidence of expressing information.

4. Students will be able to meaningfully absorb inputs in their own field of interest. 


\section{Acknowledgement}

This paper is supported by the Department of English and Literature of the University of Suwon, Association of Filipino Educators in Korea (AFEK), Reynaldo Ramos, Kim Jin Hyuk, Uhm Sunmee, Kim Joong Woo, Son In Young, Hyeong Min Mo, and Choi Eun Jae.

\section{References}

Applegate, J. R. (1969). Why don't pupils talk in class discussions. Clearing House, 44, 78-81.

Brown, A. (1992). Twenty questions. In Brown, A. (Ed.), Approaches to pronunciation teaching. London: Macmillan.

Burrill, C. (1985). The sensitive period hypothesis: A review of literature regarding acquisition of a native-like pronunciation in a second language. Paper presented at a meeting of the TRI-TESOL Conference. Bellevue, WA, 15 November.

Dansereau, D. (1985). Learning strategy research. In Segal, J. W., Chipman, S. F., \& Glaser, R. C. (Eds.), Thinking and learning skills: Relating learning to basic research (pp. 209-240). Hillsdale, NJ: Erlbaum.

Dulay, H., \& M. Burt (1977). Remarks on creativity in language acquisition. In M. Burt, H. Dulay, \& M. Finnochiaro (Eds.), Viewpoints on English as a Second Language (pp. 95-126). New York: Regents.

Field, J. (2012). The changing face of listening. In Richards, C. J., \& Renanya W. A. (Eds.), Methodology in language teaching (p. 244). New York: Cambridge University Press.

Gall, M. D., \& Gillett, M. (2001). The Discussion Method in Classroom Teaching. Retrieved January 22, 2014, from http://johnnyturtle.com/thediscussionmethod.pdf

Gardner, R., P. Smythe, R. Clement, \& L. Gliksman. (1976). Second-Language learning: a social-psychological perspective.Canadian Modern Language Review, 32, 198-213.

Grabe, W. (2012). Dilemmas for the development of second language reading abilities. In Richards, C. J., \& Renanya W. A. (Eds.), Methodology in language teaching (p. 280). New York: Cambridge University Press.

Jones, R. H. (2012). Beyond 'listen and repeat': Pronunciation teaching materials and theories of second language acquisition. In Richards, C. J., \& Renanya W. A. (Eds.), Methodology in language teaching (pp. 179-180). New York: Cambridge University Press.

Hackathorn, J. et al. (2011). Learning by doing: An empirical study of active teaching techniques. The Journal of Effective Teaching, 11(2), 40-54. Retrieved January 22, 2014, from http://uncw.edu/cte/et/articles/Vol11_2/Hackathorn.pdf

Hadjioannou, X. (2007). Bringing the background to the foreground: What do classrooms environments that support authentic discussions look like? American Educational Research Journal, 44, 370-399.http://dx.doi.org/10.3102/0002831207302173

Hunt, A., \& Beglar, D. (2012). Current research and practice in teaching vocabulary. In Richards, C. J., \&Renanya W. A. (Eds.), Methodology in language teaching (pp. 260-262). New York: Cambridge University Press.

Kelly, M. (2014). Lecture pros and cons. Retrieved January 22, 2014, from http://712educators.about.com/od/lessonplans/p/lecture.htm

Kim, J. W. (2013). English lectures sail above students. The Korean Times. Retrieved December 12, 2013, fromhttp://m.koreatimes.co.kr/phone/news/view.jsp?req_newsidx $=147484$

Kolb, D. (2013). David Kolb's learning styles model and experiential learning theory (ELT). Retrieved November 6, 2013, from http://www.businessballs.com/kolblearningstyles.htm

Krashen, S. (2002). Second language acquisition and second language learning. Retrieved August 10, 2011, from http://sdkrashen.com/SL_Acquisition_and_Learning/index.html

Lankov, A. (19 September 2013). Confucianism in Korea. The Korean Times. Retrieved September 19, 2013, from http://www.koreatimes.co.kr/www/news/opinon/2013/08/165_108831.html.

Lewis, M. (1993). The lexical approach. Hove, UK: Language Teaching Publications.

Marmet, P. R. (1977). The effects of slide-tape and lecture-discussion methods on learning gain in teaching physical 
education concepts. Retrieved January 23, 2014, from http://esirc.emporia.edu/handle/123456789/2392

McCarthy, M., \& O'Dell, F. (1994). English vocabulary in use. Cambridge: Cambridge University Press.

McCombs, B. L. (1988). Motivational skills training: Combining metacognitive, cognitive, and affective learning strategies. In Weinstein, C., Goetz, E. T., \& Alexander, P. A. (Eds.), Learning and studying strategies: Issues in assessment, instruction, and evaluation (pp. 141-169). New York: Academic Press.

Nation, I. S. P. (Ed.). (1994). New ways in teaching vocabulary. Alexandria, VA: TESOL.

Nunan, D. (2012). Listening in language learning. In Richards, C. J., \& Renanya W. A. (Eds.), Methodology in language teaching (p. 239). New York: Cambridge University Press.

Oh, S. Y. (2012). A study on effective English education at universities. Unpublished thesis, Korea University, South Korea.

Oxford, R. L. (2012). Language learning strategies in a nutshell: Update and ESL suggestions. In Richards, C. J., \& Renanya W. A. (Eds.), Methodology in language teaching (pp. 126-128). New York: Cambridge University Press.

Oxford, R. L. (1990). Language learning strategies: What every teacher should know. New York: Newburry House/Harper \& Row.

Prince, P. (1996). Second language vocabulary learning: The role of context versus translations as a function of proficiency. The Modern Language Journal, 80, 478-493. http://dx.doi.org/10.1111/j.1540-4781.1996.tb05468.x

Rajabi, S., \& Ketabi, S. (2012). Aspects of cultural elements in prominent English textbooks for EFL setting. Theory and Practice in Language Studies, 2(4), 705-712. Academy Publisher Manufactured in Finland. http://dx.doi.org/10.4304/tpls.2.4.705-712

Ramos, I.D. (2013). Diminishing cultural boundaries in the English literature and film class. In Kang, J. J. (Eds.), Advanced and Applied Convergence Letters (pp. 159-162). Seoul, South Korea: IIBC.

Ramos, I. D. (2012). The English language instruction in a South Korean university: Inputs for teaching English as a foreign language (TEFL). Unpublished doctoral dissertation, University of the Visayas, Cebu City, Philippines.

Redman, S., \& Ellis, R. (1990). A way with words book 2. Cambridge: Cambridge University Press.

Reigeluth, C. (1992). Elaboration theory. Retrieved January 17, 2014, from http://www.instructionaldesign.org/theories/elaboration-theory.html

Rost, M. (1994). Introducing listening. London: Penguin.

Schumann, J. (1975). Affective factors and the problem of age in second language acquisition. Language Learning, 25, 209-235. http://dx.doi.org/10.1111/j.1467-1770.1975.tb00242.x

Seliger, H. (1977). Does practice make perfect? A study of interaction patterns and L2 competence. Language Learning, 27, 264-278. http://dx.doi.org/10.1111/j.1467-1770.1977.tb00122.x 